\title{
Wettability of graphene and its control
}

\author{
Jangyup Son ${ }^{\dagger}$ \\ Functional Composite Materials Research Center, Korea Institute of Science and \\ Technology, Jeollabuk-do, 55324, Republic of Korea
}

\section{그래핀의 습윤성 및 제어기술}

\author{
손장엽 ${ }^{\dagger}$ \\ 한국과학기술연구원 기능성복합소재연구센터
}

(Received May 22, 2020; Accepted June 4, 2020)

\begin{abstract}
The wettability is one of the most fundamental properties of a material surface. Especially, graphene, twodimensional (2D) surface material in which all the carbon atoms are exposed to the environment, is the best choice of template to study about the surface wettability. However, most studies have focused on the mechanical and electrical properties of graphene, not the surface wettability. This review article covers the wettability of graphene and provides recent research regarding the engineering of the surface wettability. This paper would be helpful for researchers working in this field and provides perspective for future carbon-liquid interacting applications.
\end{abstract}

Keywords: graphene, wettability, water-carbon interaction, surface topography, chemical functionalization

\section{1. 서론}

표면(surface)이란 원자 한 층 또는 수 나노미터 깊이 의 원자 및 분자로 구성된 재료의 최외곽 층으로서, 외 부 물질과 접촉하여 상호작용하는 가장 첫 번째 장소이
다. 화학적 결합 및 반응, 표면 마찰력, 빛의 회절 및 반 사, 물질 간의 응집력 등 다양한 물리/화학적 반응 현상 이 재료의 표면으로부터 시작되고, 열거한 반응들은 표 면의 특성에 매우 큰 영향을 받는다. 이러한 이유로 인 해 재료의 표면을 이해하고 제어하기 위한 표면공학

${ }^{\dagger}$ Corresponding Author: Jangyup Son

E-mail: jayson@kist.re.kr 
(surface engineering)이 발전하였고, 빛의 난반사를 이용한 오색찬란한 장신구나 실내장식 용품, 선박의 내 산화막 및 자동차 유리의 발수/방수 코팅과 같은 거시 적 규모의 표면처리부터 나노 입자의 표면 조절을 통해 입자의 물성이나 화학적 반응성을 제어하는 나노 크기 의 표면처리까지 광범위한 표면 관련 응용 연구가 활발 히 진행되었다. 앞서 열거한 예들은 극히 일부분일 정도 로 표면처리 응용 분야는 매우 다양하고 많은 연구가 진 행됐으며, 이를 통해 표면이 재료의 연구개발 및 산업적 응용에 얼마나 핵심적인 역할을 하고 있는지 가늠할 수 있다.

재료의 표면과 접촉하는 다양한 외부 물질 중, 물은 대기 중에 필히 존재하고 생체를 구성하는 주성분임과 동시에 대부분의 화학작용에 관여하는 등 재료의 표면 연구에 가장 핵심적인 물질 중 하나이다. 이러한 이유 로, 재료의 여러 표면 특성 중 본 논문에서 다루고자 하 는 것은 습윤성(wettability)이다. 이는 재료의 표면이 액체와 접촉을 유지하려는 정도, 즉 젖음의 정도를 의미 하며, 재료의 표면과 액체가 접촉했을 때 발생하는 분자 간 상호작용에 의해 그 정도가 정해지고, 물과 고체 표 면 간의 접촉각(contact angle, $\theta_{\mathrm{c}}$ )으로 그 정도를 측정 하고 구분할 수 있다(Fig. 1). 물 분자 간의 응집 에너 지(binding energy)가 재료 표면에 대한 흡착 에너지 (absorption energy)보다 약하면 물 분자는 재료 표면 에 퍼지려는 경향을 보이고 접촉각이 $90^{\circ}$ 보다 낮은 상태 가 되는데, 이를 친수성(hydrophilicity)이라 한다. 반 면, 물 분자 간의 응집에너지가 표면에 대한 흡수에너 지보다 강하면 물은 표면에 퍼지지 않고 구형에 가까운

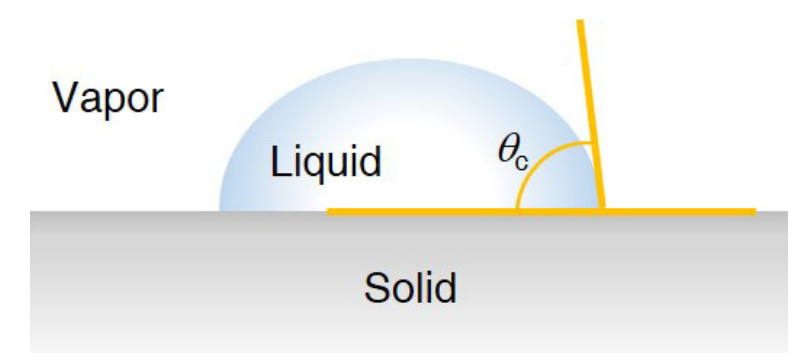

Fig. 1. 고체와 액체 표면이 이루는 접촉각(contact angle, $\theta_{\mathrm{c}}$ )을 묘 사한 도식.
형태로 응집되어 접촉각이 $90^{\circ}$ 보다 높아지는 상태가 되 는데, 이를 소수성(hydrophobicity)이라고 한다. 이러 한 습윤성의 정도는 표면의 형태(surface topography) 와 화학적 개질(chemical modification)에 주로 의존하 는데 ${ }^{1)}$, 이를 제어함으로써 재료의 표면과 물이 반응하 는 정도를 이용한 다양한 응용이 가능하다. 예를 들어, Fig. 2(a)와 같이 딱정벌레가 껍질로 안개를 모아 물방 울을 만드는데서 착안한 안개 수확(fog harvesting) $)^{2-5)}$, Fig. 2(b)와 같이 물이 스며들지 않는 연잎을 모방한 초소수성(super-hydrophobicity) 표면의 자가 세정 (self-cleaning) $)^{6,7)}$ 등, 주로 자연에서 영감을 얻어 시작 된 사례들로부터 시작하여 새로운 구조의 다기능 표면 소재 및 소자로의 개발로 점차 확대되고 있다.

재료의 표면에 관한 연구는 삼차원 벌크 재료(3D bulk materials)를 이용한 연구가 주로 진행되었으나, 그래핀의 발견 이후 최근에는 모든 원자가 외부 환경에 노출된 이차원 재료(2D materials)를 이용한 연구로 이 어지는 추세이다. 이차원 재료는 표면으로만 이루어진 구조로 존재하는데, 이러한 점은 표면 연구에 필요한 재 료의 표면만을 집중적으로 다룰 수 있다는 점에서 큰 의 미가 있다. 또한, 벌크 재료와는 다르게 표면의 특성 제 어를 통하여 재료의 전기/광학적 특성도 동시에 제어할 수 있는 장점도 있어, 이차원 재료를 이용한 표면 연구 는 표면 공학 분야에서 매우 흥미로운 연구 주제가 되었 당. 그 중심엔 탄소 원자 한 층으로 이루어진 그래핀이 핵심적인 재료로 사용되고 있는데, 고품질의 대면적 합 성 기술 및 전사 방법 개발, 쉽게 구겨지거나 늘어나는 구조 변형의 용이함, 그리고 화학적 기능화(chemical functionalization)를 통한 표면 제어에 대한 기술 개발 에 힘입어 그래핀 자체의 표면 연구 뿐만 아니라 그래핀 으로 코팅된 재료의 표면 연구가 활발히 진행 중이다. 더욱이 그래핀 기반의 담수화 필터 ${ }^{9)}$, 이차전지 분리막 ${ }^{10)}$, 슈퍼캐패시터 전극 ${ }^{10)}$ 등 대부분의 탄소 기반 전자 소 자는 물과의 접촉이 불가피하므로, 모든 액체-고체 상 호작용(liquid-solid interaction) 중 액체-탄소 상호작 용(liquid-carbon interaction)은 매우 흥미로운 주제 중 하나임이 틀림없다 ${ }^{1)}$. 그만큼 물의 접촉과 관련된 그 
(a)
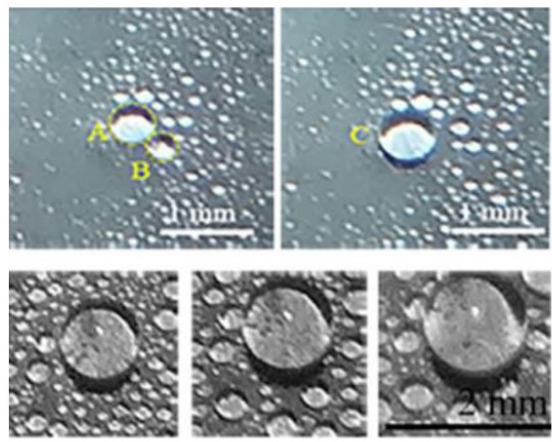

(b)

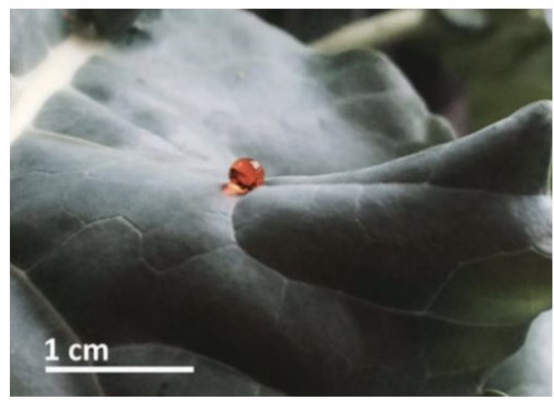

(c)

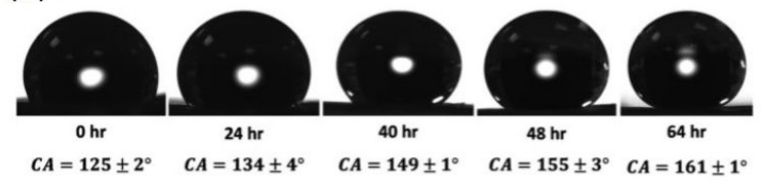

Fig. 2. (a) 물방울의 유착(coalescence) 및 성장을 보여주는 광학 이미질. (b) 브로컬리 잎 위의 물방울의 형상). (c) 손상된 브로컬리 잎 위 물방울의 시간에 따른 접촉각 변화).

래핀의 습윤성 연구는 매우 핵심적인 연구 주제라고 볼 수 있다 ${ }^{1,11-14)}$. 이러한 그래핀 습윤성 연구의 중요성에도 불구하고, 지금까지 대부분의 연구는 그래핀의 기계적 특성이나 전기적 특성에 집중되었고, 물과의 접촉을 통 한 표면 습윤성에 대한 연구는 상대적으로 덜 중요하게 인식되었다.

본 리뷰 논문에서는 지금까지 발표된 그래핀의 습윤 성 및 제어와 관련된 핵심 연구 결과에 대해 논의한다. 특히 그래핀의 구조 변형 및 표면의 화학적 기능화를 활 용한 습윤성 제어 기술에 대해 소개한다. 본 논문은 그 래핀의 습윤성에 대한 연구를 시작하는 연구자나 비전 문가들이 참고할 수 있는 수준의 내용을 다루고 있으며, 보다 자세한 정보를 원하는 독자들은 본 논문에 언급된
참고문헌 및 그래핀의 습윤성과 관련된 다른 리뷰 논문 들을 참고하면 도움이 될 것이다.

\section{2. 그래핀의 습윤성(wettability of graphene)}

표면 결함이 없는 이상적인 그래핀은 평평한 구조와 쌍극자(dipole)가 없는 전기적 특성으로 인해 소수성 을 갖는다고 알려져 왔고, 그래핀의 습윤성에 대한 많 은 연구 결과들은 그래핀이 소수성이라고 주장하고 있 다,11-14). 그러나 그래핀이 소수성을 보이는 이유는 기 판의 습윤성을 그대로 따르는 습윤 투명성(wetting transparency $)^{15)}$ 에 의해 소수성 기판의 표면 특성 이 투영된 결과 때문이거나 대기 중에 존재하는 하이 드로카본(hydrocarbon)과 같은 공중 오염물(airbone contaminants)이 그래핀에 흡착된 환경적인 요인 때문 이고 ${ }^{1,16)}$, 실제 그래핀의 고유 습윤성은 친수성이라고 보 고하는 연구 결과들도 있다,112-14). 다양한 외부환경 요인 에 쉽게 영향을 받는 그래핀의 특성으로 인해 실험적으 로 그래핀의 고유 습윤성을 증명하기란 상당히 도전적 인 일이고, 이런 이유로 인해 그래핀의 고유 습윤성에 대한 명확한 결론을 내리지 못하고 있는 상황이다.

Highly oriented pyrolytic graphite (HOPG)와 같 은 natural graphite의 습윤성에 대한 초기 연구 ${ }^{11)}$ 시절 부터 지금까지, 그래핀의 고유 습윤성이 소수성인지 친 수성인지에 대한 논란은 여전히 진행 중이다 ${ }^{1,12-14)}$. 이러 한 논란을 해결하기 위해선 기판의 영향이 없는 이상적 인 그래핀을 가정한 이론 계산의 도움이 필요하고, 이를 위해 free-standing 그래핀 상황을 연출한 시뮬레이션 연구가 진행되었다 ${ }^{1,12-14)}$. 그러나 free-standing 그래핀 을 가정한 계산 역시 매우 도전적이고, 그래핀-물 상호 작용 모델(graphene-water interaction model)을 어 떤 것을 선택하느냐에 따라 계산 결과가 상이한 값을 보 이는 등 시뮬레이션을 통한 그래핀의 고유 습윤성 확인 연구도 명확한 결론을 내리지 못하고 있는 실정이다 ${ }^{17}$ ${ }^{20)}$. 그러나 그래핀의 습윤성에 대해 명확히 정의하려 노 력하는 것 보단, 그래핀의 습윤성에 영향을 주는 요인들 에 대해 충분히 이해하고 이를 이용하여 그래핀 습윤성 

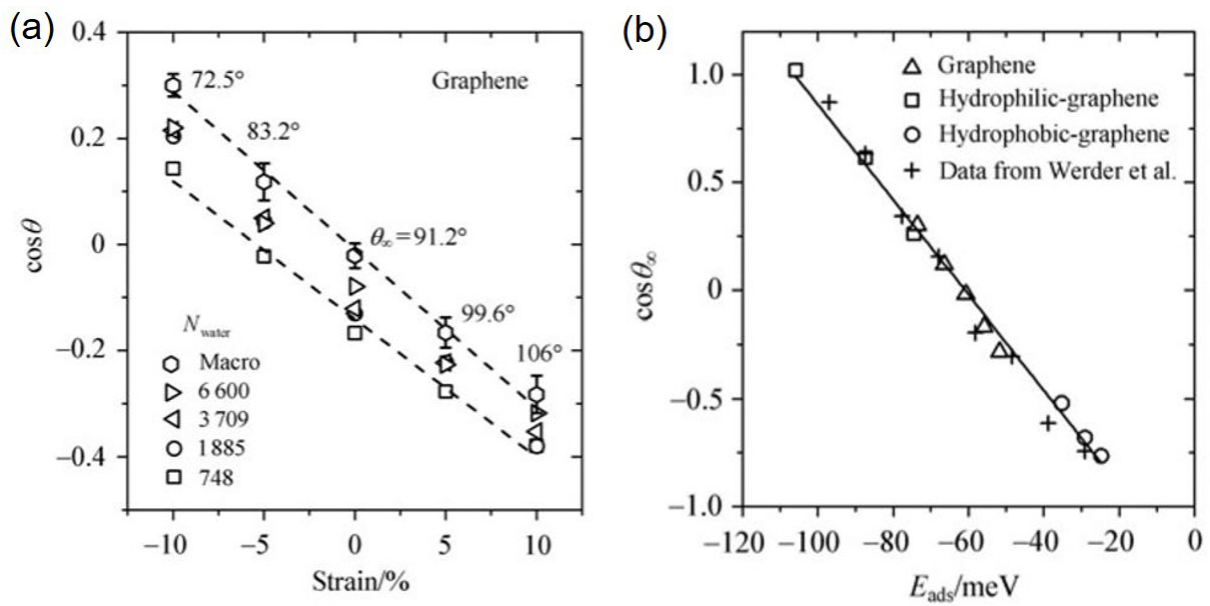

Fig. 3. (a) 그래핀에 가해진 biaxial strain에 대한 $\cos \theta$ 의 선형 관계 계산 결과 ${ }^{22}$. (b) Strain이 가해진 그래핀, 친수성 표면, 소수성 표면 위 물 분자의 흡착 에너지(adsorption energy)에 대한 $\cos \theta_{\infty}$ 의 선형 관계 계산 결과 ${ }^{22)}$.

의 제어에 활용하기 위한 노력을 하는 것이 휠씬 유익할 것이다. 본 리뷰 논문에서도 그래핀의 고유 습윤성과 관 련한 수 많은 연구 결과들에 대한 소개는 간략히 하기로 하고, 그래핀의 습윤성을 제어할 수 있는 연구 결과들의 소개에 집중하기로 한다. 그래핀의 고유 습윤성에 대해 더 많은 정보를 얻고자 한다면 본 논문의 참고 문헌들을 읽어보면 도움이 될 것이다.

\section{3. 그래핀 습윤성 졔어 기술}

소수성의 그래핀은 물의 접촉을 줄여 그래핀 기반 전 자 소자의 공정 과정이나 작동 중에 발생하는 오염을 줄일 수 있고, 친수성의 그래핀은 바이오재료(bioma terials)나 microfluidic system과 같은 연구에 응용할 수 있는 등, 그래핀 습윤성의 제어는 그래핀을 광범위한 응용 연구에 활용할 수 있게 해준다 ${ }^{1}$. 그만큼 그래핀의 습윤성을 제어하는 기술에 대한 이해와 후속 연구가 중 요하며, 이를 위해 습윤성 제어 기술에 대한 핵심 연구 결과를 살펴보도록 하겠다. 지금까지 다양한 그래핀 습 윤성 제어 기술이 보고되었으나 ${ }^{1,12-14)}$, 본 리뷰 논문에서 는 표면 구조(surface topography)의 변형을 이용한 방 법과 화학적 기능화(chemical functionalization)를 통 한 습윤성 제어 방법에 대해서만 집중하겠다.

\section{1 표면 구조(surface topography)를 활용한 제어}

탄소 원자 간의 강한 공유결합과 원자 한 층의 얇은 두께로 인해 그래핀을 늘리거나 휘어지게 변형시킬 수 있고, 이러한 우수한 기계적 특성으로 인해 그래핀은 유연소자(flexible devices)의 핵심 재료로 주목받았다 21). 그러나 그래핀의 변형 공학(strain engineering)은 그래핀 기반 전자소자 연구에만 국한되어 활용되는 것 이 아닌, 그래핀의 습윤성 제어 연구에도 활용할 수 있 다. Tsinghua University 연구진은 그래핀에 가해진 strain에 따른 습윤성의 변화를 molecular dynamic (MD) 시뮬레이션으로 예측하였다 ${ }^{22)}$. 연구 결과에 따르 면, 그래핀(strain이 $0 \%$ 일때 $91.2^{\circ}$ 의 접촉각을 갖는 상 태로 설정)에 가해진 biaxial strain이 $-10 \%$ 에서 $10 \%$ 로 변화함에 따라 그래핀의 contact angle은 $72.5^{\circ}$ 에서 $106^{\circ}$ 으로 선형 증가하였다(Fig. 3(a)). 이러한 strain과 접촉각 간의 선형 관계는 그래핀 표면 위에 접촉한 물 분자의 흡착 에너지(adsorption energy, $\mathrm{E}_{\mathrm{ads}}$ )와 $\cos \theta_{\infty}$ (cosine of the macroscopic contact angle) 선형 관계 가 주된 이유이다(Fig. 3(b)). 즉, 그래핀 내 탄소 원자 간의 거리를 변화시켜 습윤성을 가역적으로 제어할 수 있음이 시뮬레이션을 통하여 예측된 것이다. 그러나 그 래핀을 활용하는 대부분의 응용 소자는 그래핀을 지지 할 기판이 필요하여 그래핀에만 strain을 가하는 것은 


\section{특 집 미 손장엽}

(a)

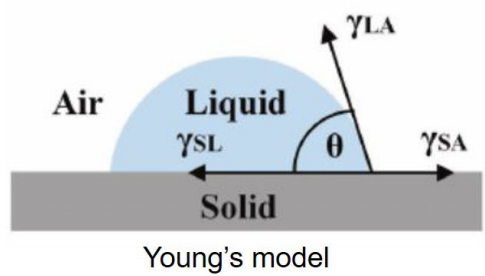

(b)

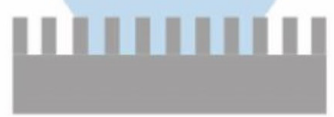

Wenzel's model (c)

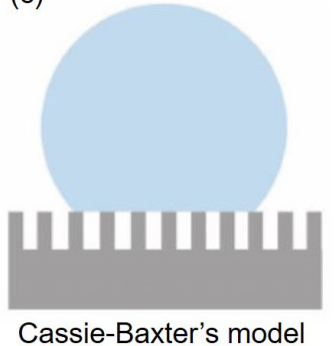

Fig. 4. (a) Young's model, (b) Wenzel's model, 그리고 (c) Cassie-Baxter's model ${ }^{23)}$.

사실상 불가능하고, 더욱이 음의 방향으로 strain을 가 하는 것은 매우 도전적이다. 물론 수축/팽창이 가역적이 고 그래핀과 접착력이 좋은 기판을 이용하면 가능할 수 도 있겠으나, 이러한 하부 기판을 선정하기 위해선 더 많은 실험적 검증이 필요하다.

다음으로 소개할 내용은 그래핀의 surface topography 를 활용한 습윤성 제어 관련 연구들이다. 이들을 소개하 기에 앞서, 고체의 표면과 물의 젖음 현상을 설명하는 classical model들에 대한 설명이 필요하다. 평평한 고 체 표면에 물이 닿은 경우, 습윤성은 고체의 표면 자유 에너지(surface free energy)에 의해 결정되고, 이러한 관계를 설명하기 위해 Young's equation $\left(\gamma_{\mathrm{SA}}=\gamma_{\mathrm{SL}}+\gamma_{\mathrm{LA}}\right.$ - $\cos \theta$ )이 사용된다 ${ }^{23,24)}$. Fig. 4(a)에 있는 $\gamma_{\mathrm{SA}}, \gamma_{\mathrm{LA}}, \gamma_{\mathrm{SL}}$, $\theta$ 는 각각 고체의 표면 자유 에너지, 액체의 표면 자유 에 너지, 고체-액체 계면의 자유 에너지, 접촉각을 의미하 고, 고체의 표면 자유 에너지가 낮아짐에 따라 접촉각 이 증가하게 된다. 그러나 실제 고체의 표면은 이상적 으로 평평하지 않고, surface topography가 습윤성에 영향을 주기 때문에 Young's equation만으로 습윤성 을 설명하는 것은 역부족이다. 따라서 추가적인 두 모델, Wenzel model과 Cassie-Baxter model을 사용하여 설명하는 것이 필요하다(Fig. 4(b)와 4(c)). Wenzel's model은 물이 울퉁불퉁한 고체 표면의 홈을 완전히 채 운 상황을 가정한다 ${ }^{25)}$. 반면에 Cassie's model은 물 이 공기 포켓(air pocket)이 있는 표면 위에 놓여진 상 황을 가정한다 ${ }^{26)}$. 이 두 모델을 종합해보면, Young'S model에서 다루는 고체의 표면 자유 에너지 외에도 접 촉각에 영향을 추가적인 요인은 표면 거칠기(surface roughness)와 고체 표면에 갇힌 공기 포켓(air pocket) 이라는 점이고, 높은 접촉각을 얻기 위해선 표면 거칠기 가 심하거나 더욱 많은 공기 포켓이 있어야 함을 알 수 있다.

다시 본론으로 돌아와 surface topography를 이 용한 연구들을 소개한다. Tsinghua University 연구 진은 패터닝한 $\mathrm{Si}$ 기판에 microwave plasma CVD (MPCVD) 방법으로 그래핀을 성장시켜 초소수성 (superhydrophobicity)의 표면 제작 방법을 보고하 였다 ${ }^{27)}$. Fig. 5(a)와 (b)에서 볼 수 있듯이 $\mathrm{Si}$ (111) 기 판에 미세 필러(micropillar array) 구조를 패터닝한 뒤 microwave plasma chemical vapor deposition (MPCVD) 방법으로 수직 정렬된 그래핀을 성장시켰고, $152^{\circ}$ 의 접촉각을 갖는 초소수성 표면을 제작하는데 성공 하였다 (Fig. $5(\mathrm{c})$ 와 $(\mathrm{d})$ ). 수직 정렬된 그래핀의 구조 그 자체로도 소수성에 영향을 주지만, Fig. 5(d)에서 볼 수 있듯이 패터닝된 기판과 물 사이에 존재하는 공기 포켓 으로 인해 초소수성에 가까운 습윤성으로의 제어가 가 능하였으며, 본 연구의 표면 습윤성은 Cassie's model 을 바탕으로 해석이 가능하다.

Surface topography를 이용한 또 다른 예로, 미국 Rensselaer Polytechnic Institute 연구진은 삼차원 그 래핀 폼(3D graphene foam network)를 이용한 초소 수성 결과를 보고하였다 ${ }^{28)}$. 폼(foam) 구조의 $\mathrm{Ni}$ 템플레 이트에 template-directed CVD 방식으로 그래핀을 합 성한 뒤 $\mathrm{Ni}$ 을 엣칭시켜 수백 마이크로미터 사이즈의 기 공(pore)을 갖는 그래핀 폼을 제작하였고(Fig. 6(a)),이 렇게 제작한 그래핀에 테플론(Teflon)을 코팅하여 표면 


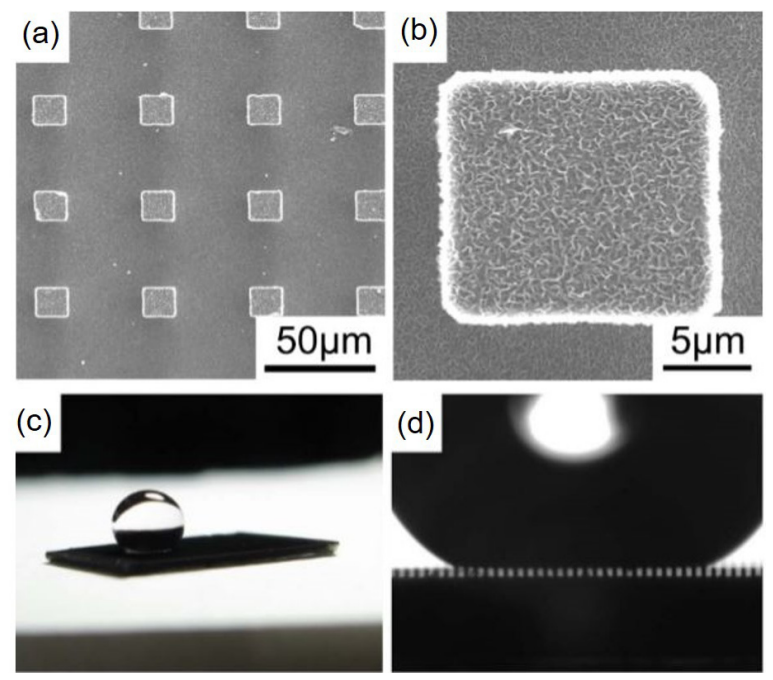

Fig. 5. (a,b) 실리콘 미세구조 위에 성장시킨 fewlayer graphene의 $\mathrm{SEM}$ 이미지와 (c) 그 위에 물을 올린 사진. (d) 미세 구조 위의 물방울이 접촉한 형태를 보여주는 광학사진. 공기로 채워진 공간이 물방울과 고체 표면사이에 보임ㄱ).

습윤성을 확인하기 위한 샘플을 준비하였다. 그 결과, Fig. 6(b)에서 볼 수 있듯이 약 $163^{\circ}$ 의 접촉각을 보이는 초소수성이 확인되었다. 게다가 그래핀 폼의 구조로부 터 기인하는 우수한 탄성력과 높은 기계적 강도로 인해 물이 표면에서 튕기는 리바운딩(rebounding) 현상도 관 찰되었다(Fig. 6(c)). 즉, 폼 형태의 그래핀 구조에 의한 초소수성과 강한 기계적 강도를 동시에 검증한 사례라 고 볼 수 있다.

앞서 소개한 연구 결과들은 template를 활용하여 그 래핀을 합성하고 그 결과로 얻어진 그래핀의 surface topography를 이용한 습윤성 확인 실험들인데, surface topography의 제어를 통한 습윤성의 변화를 관찰할 수 없다는 한계가 있다. 그러나 Duke University 연구 진은 신축성있는 기판 위에 전사한 그래핀의 surface topography를 변형시켜 습윤성을 제어하는 연구 결과 를 보고하였다 ${ }^{29)}$. Fig. 7(a)와 (b)에서 볼 수 있듯이, 전 방향으로 늘린 신축성 $\mathrm{VHB}$ 필름 위에 그래핀을 전사 한 뒤 수축시키면 그래핀이 구겨지는데(crumpling), 이 러한 구겨짐의 정도를 조절하면 앞서 언급한 Wenzel's model과 Cassie's model을 모두 포함할 수 있는 표 면 구조의 제어가 가능하고, 이로 인해 습윤성의 제
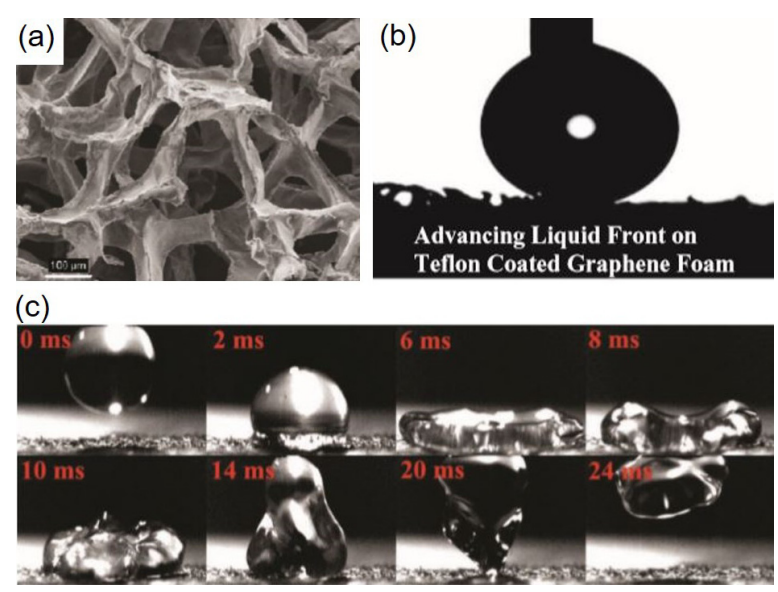

Fig. 6. (a) Teflon이 코팅된 그래핀 폼의 SEM 이미지. (b) Teflon이 코팅된 그래핀 폼 위의 물방울을 촬영하 이미지. 약 $163^{\circ}$ 의 접촉각을 보이는 소수성 표면 특성이 관찰됨. (c) 물방울이 튕기는 현상을 촬영한 영상의 스냅샷 이미지 ${ }^{28)}$.

어가 가능하게 된다. Fig. 7(c)와 (d)에서 볼 수 있듯 이, crumpled graphene은 소수성의 표면 특성을 보 이고, 약 $50 \%$ 이상의 compressive strain에서는 촘 촘한 홈의 형상으로 인해 공기 포켓이 갇힌 표면을 묘 사하는 Cassie's model을 따르고, $50 \%$ 이하에서는 공 기 포켓이 없는 Wenzel's model을 따르는 것이 확인 되었다. 이처럼 그래핀의 강한 기계적 강도, 유연함 및 신축성은 벌크 재료로는 불가능한 표면 구조의 가역 적 변형과 습윤성 제어를 가능하게 하고, mechanical strain engineering을 이용한 그래핀 습윤성의 가역 적 제어는 lab-on-chip systems, tunable optical lenses, microfluidic tools 등 다양한 micro/nanoelectromechanical system과 관련된 응용 연구로 활용 될 수 있음을 시사한다.

\section{2 화학적 기능화(chemical functionalization)를 활용한 제어}

그래핀의 표면 습윤성을 제어할 수 있는 또 다른 방법 은 표면의 화학적 기능화(chemical functionalization) 이다. 탄소 원자들이 $\mathrm{sp}^{2}$ 결합 구조로 연결된 그래핀은 파이 전자 네트워크( $\pi$-electron network)에 의해 표 면이 화학적으로 안정하지만, 플라즈마나 반응성 기체 를 이용한 적절한 표면 처리 기술을 통하여 그래핀과 이 
(a)
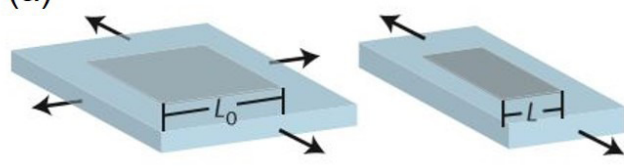

(c)

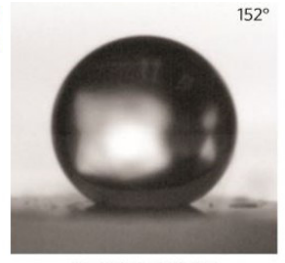

Crumpled graphene (b)

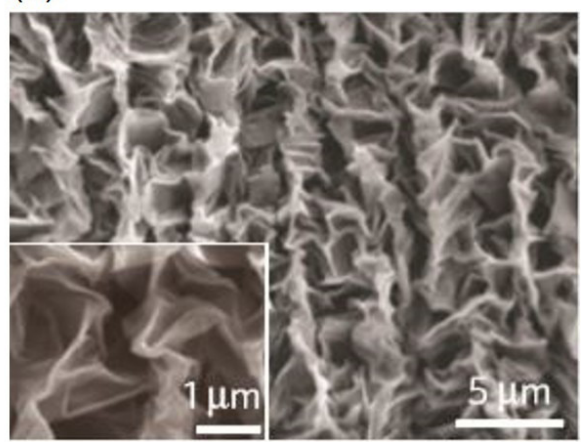

(d)

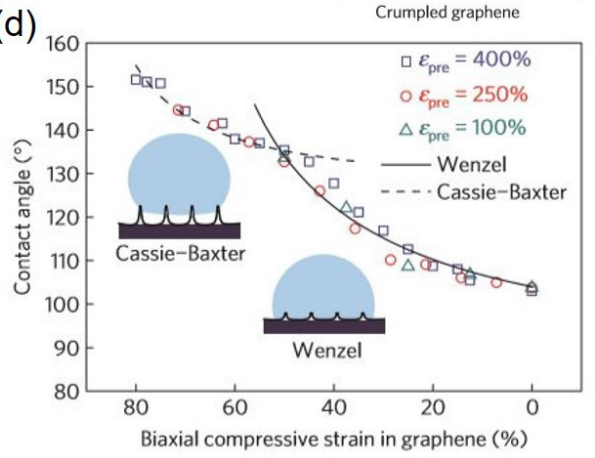

Fig. 7. (a) Crumpled graphene을 제작하는 방법을 묘사하는 모식도. (b) Crumpled graphene 표면의 SEM 이미지. (c) Crumpled graphene 위 물방울을 촬영한 사진. $152^{\circ}$ 의 접촉각이 측정되었고, 소수성의 표면이 확인됨. (d) 그래핀에 가해진 biaxial compressive strain에 대한 접촉각의 변화 결과 ${ }^{29)}$.

종 원자(foreign atom) 등의 외부 물질이 공유 결합된 $\mathrm{sp}^{3}$ 결합 구조를 만들 수 있다. Fig. 8과 같이, 그래핀의 표면에 이종 원자가 화학적으로 결합되면 비대칭적인 전자의 공간 분포에 의해 표면 전하가 유도되고, 극성 (polar)의 물 분자는 화학적으로 기능화된(표면 전하를 갖는) 그래핀 표면에 전기적으로 인력을 느껴 달라붙게 된다. 이러한 이유로, 앞서 소개한 surface topography 를 이용한 습윤성 제어가 소수성의 그래핀을 만들기 위 한 방법으로 주로 사용되었다면, 지금 소개하는 화학적 기능화를 통한 습윤성의 제어는 주로 친수성 그래핀을 만들기 위한 방법으로 사용된다.

National University of Singapore의 연구진은 $\mathrm{SiC}$ 기판 위에 성장시킨 에피택셜 그래핀(epitaxial graphene) 에 저에너지 산소 플라즈마(low-power oxygen plasma) 처리를 이용하여 소수성의 그래핀을 친수성으로 변형 시킨 결과를 보고하였다 ${ }^{30}$. Fig. 8과 같이, 애피택셜 그 래핀에 산소 플라즈마를 처리하여 접촉각이 $92.5^{\circ}$ 에서 $55.1^{\circ}$ 로 낮아지는 것을 볼 수 있으며, 이는 소수성에 가 까운 그래핀이 친수성으로 변형된 것을 의미한다. 또한 열처리 후 표면에 결합되어 있는 산소를 모두 제거한 그 래핀의 접촉각이 초기 애피택셜 그래핀과 유사한 $87.3^{\circ}$
으로 회복되는 것을 볼 수 있는데, 이는 플라즈마 처리 과정 중 결함의 발생이 없어서 열처리 후 산소 원자가 제거된 뒤 원래의 그래핀 상태로 회복되는 것을 의미한 다. 본 연구에서는 산소 플라즈마 처리에 의한 표면의 하이드록사이드(hydroxide) 형성이 친수성의 원인이라 고 밝히고 있으며, 이는 비대징 전자 분포를 보이는 외 부 결합 물질로부터 기인한 표면 전하가 극성의 물분자 를 끌어당겨 친수성을 나타낸다는 원리와도 동일함을

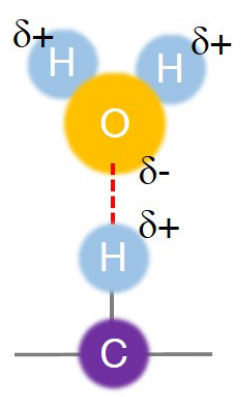

Single water molecule on partial positive charge

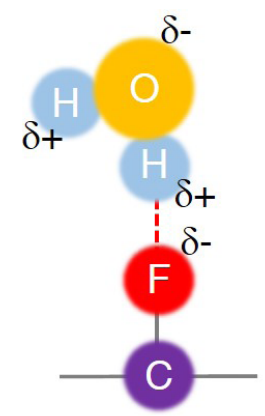

Single water molecule on partial negative charge
Fig. 8. 표면 전하를 갖는 화학적 기능화 그래핀 표면 위 물 분자의 흡착을 묘사하는 모식도. 수소와 불소가 화학적으로 흡착된 기능화 그래핀을 가정함. 

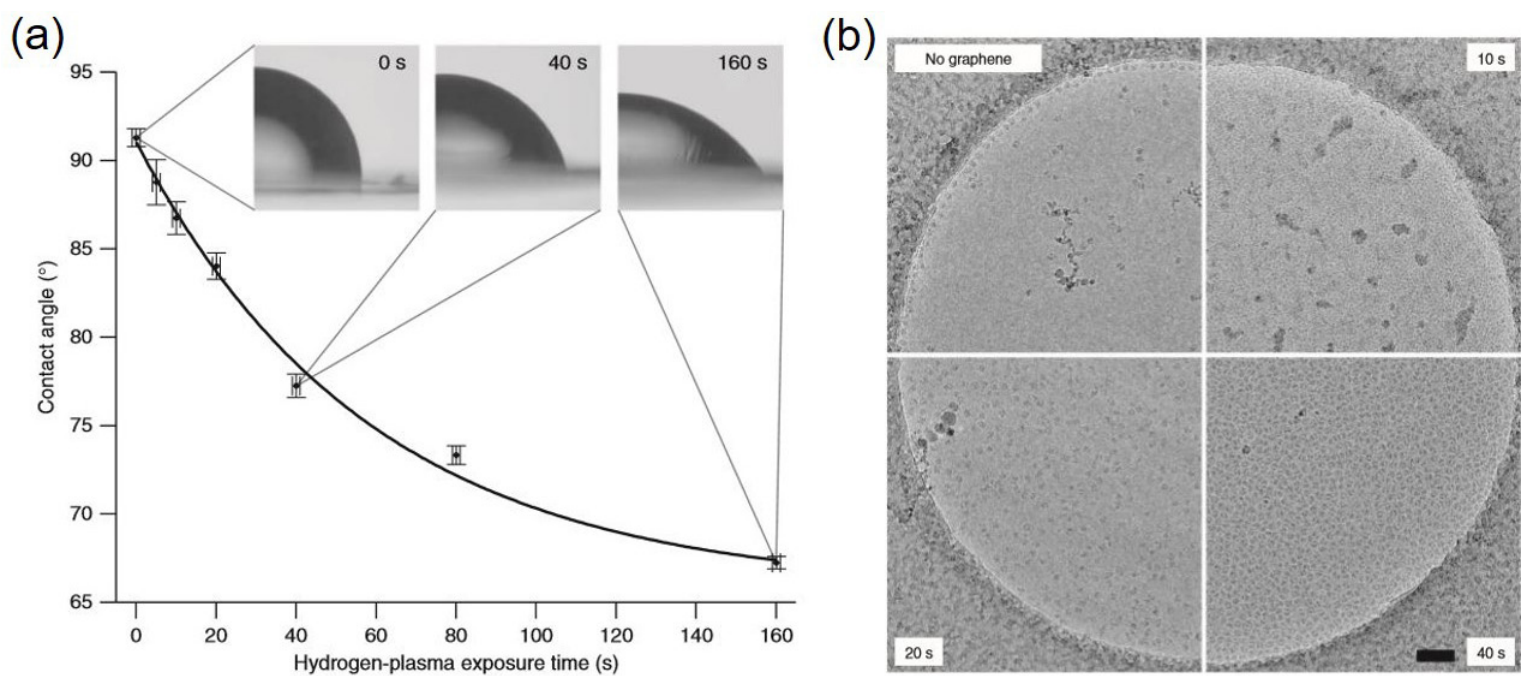

Fig. 9. (a) 수소 플라즈마 처리 시간에 따른 접촉각의 변화. (b) 수소화 그래핀 표면 위 단백질의 흡착을 보여주는 SEM 이미지. 수소 플라즈마 처리 시간이 증가함에 따라 단백질의 흡착률이 높아지는 것을 볼 수 있음1).

알 수 있다.

영국의 Medical Research Council Laboratory of Molecular Biology 소속 연구진은 저에너지의 수소 플라즈마 조사 기술로 제작한 친수성 수소화 그래핀 (hydrogenated graphene)을 사용하여 단백질 흡착 연 구 결과를 보고하였다 ${ }^{31}$. Fig. 9(a)와 같이, 수소 플라즈 마의 처리 시간이 증가함에 따라 접촉각이 $91^{\circ}$ 에서 $66^{\circ}$ 으로 감소하였고, 이는 수소 플라즈마 처리를 이용하여 소수성의 그래핀을 친수성으로 변형시킬 수 있음과 동 시에 처리 시간에 따른 습윤성 제어가 가능함을 보여준 다. 또한, 친수성이 증가함에 따라 단백질이 흡착되는 정도가 더욱 강해지는 것을 볼 수 있는데(Fig. 9(b)), 이 는 친수성 그래핀의 제작 및 제어가 습윤성 연구뿐만 아 니라 생물 세포와의 상호작용을 연구하는 분야에도 활 용될 수 있음을 보여준다.

최근 연세대학교 연구진은 저에너지의 수소 플라즈 마 처리를 이용하여 그래핀을초친수성(접촉각이 $10^{\circ}$ 이 하인 상태)에 가까운 상태로 제어한 뒤 암세포 $(\mathrm{GFP}-$ $\mathrm{MCF}-7)$ 를 흡착시키는 결과를 보고하였고 ${ }^{32)}$, 이는 그래 핀의 습윤성 제어를 생물 세포 흡착 연구와 연결시킨 또 다른 사례로 볼 수 있다. 연구진은 저에너지의 간접식 수소 플라즈마(indirect or remote hydrogen plasma)
를 이용하여 pore나 void와 같은 구조적 결함 발생없이 $25 \%$ 의 수소 흡착률을 보이는 $\mathrm{C}_{4} \mathrm{H}$ 타입의 수소화 그래 핀(hydrogenated graphene)을 제작하였고, $16^{\circ}$ 의 접촉 각을 보이는 초친수성에 가까운 상태까지 표면의 습윤 성을 제어하는데 성공하였다(Fig. 10(a)). 또한, 친수성 이 증가함에 따라 암세포의 흡착률이 증가하는 결과를 응용하여 초친수성 수소화 그래핀으로 패터닝한 영역에 개별 암세포를 격리 배향하는 결과를 보여주었다(Fig. 10(b)와 (c)). 이 결과는 배양액이나 혈액 내에 존재하는 적은 양의 암세포를 높은 확률로 검출할 수 있는 바이오 센서로의 응용을 가능하게 하고, 서로 뭉쳐서 자라려는 암세포를 격리 배양할 수 있는 기판으로 사용하여 암세 포의 개별 연구 및 세포 간의 상호작용 연구에도 활용할 수 있음을 보여준다.

앞서 소개한 산소 및 수소를 이용한 그래핀의 화학 적 기능화는 전하를 갖는 표면과 극성인 물분자의 결합 을 이용한 친수성으로의 제어라는 점에서 공통적이었 다. 하지만 불소 $(\mathrm{F})$ 를 이용한 그래핀의 화학적 기능화의 경우, 불화 그래핀(fluorinated graphene)이 친수성뿐 만 아니라 소수성을 보인다고 보고하는 연구 결과들이 다수 있다. 소수성 결과를 보고하는 연구팀들은 저마다 $\mathrm{C}-\mathrm{F}$ 결합에 의한 표면 에너지 감소를 그 원인으로 주장 


\section{특 집 ㅁㅃ 손장엽}

(a)

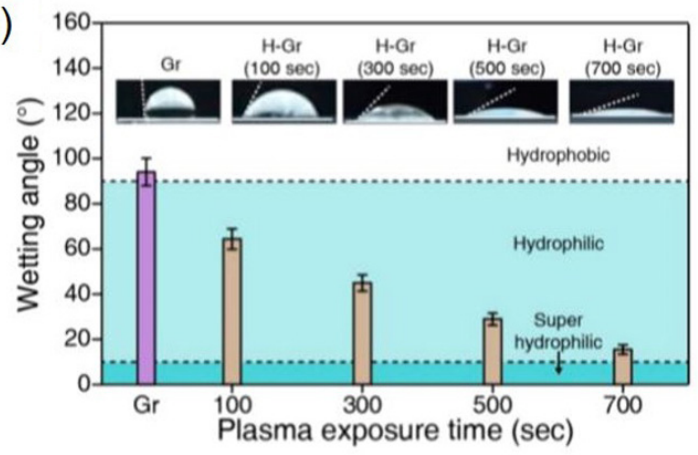

(b)

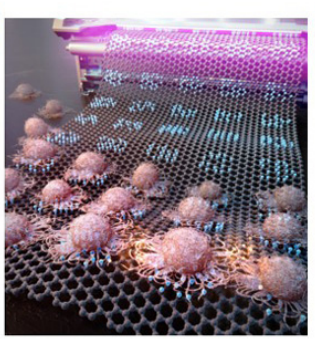

(c)

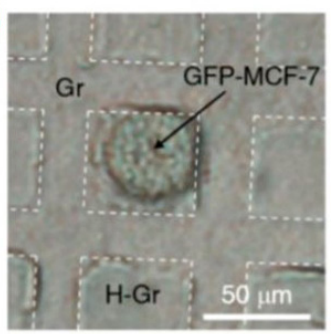

Fig. 10. (a) 수소 플라즈마 처리 시간에 따른 그래핀의 접촉각 변화 결과. (b) 패터닝된 수소화 그래핀 표면 위 암세포의 흡착 을 묘사하는 모식도. (c) 패터닝한 수소화 그래핀 표면 위 에 개별 흡착된 암세포의 광학 현미경 사진 ${ }^{32}$.

하고 있으나(혹은 그 원인에 대해 명확한 근거를 제시하 지 않는 결과들도 있다), 불소 원자 표면에 유도된 음전 하와 극성 물분자와의 전기적 인력에 대해선 명확한 설 명과 근거를 제시하지 못하는 상황이다. 또한, $\mathrm{C}-\mathrm{H}$ 결 합 역시 표면 에너지를 낮추기 때문에 화학적으로 기능 화된 불화 그래핀 표면의 소수성을 표면 에너지만으로 해석하기에는 부족한 감이 있다. 실험적 검증이 더욱 필 요하겠으나, 불화 그래핀의 소수성을 설명하기 위해선 전하를 띠는 원인 물질의 간격이 critical length보다 낮 으면 소수성을 나타낼 수 있다는 계산 결과로 ${ }^{33)}$ 해석하 는 것이 보다 설득력이 있어 보인다(Fig. 11(a)). 해당 연 구 결과에 따르면, 전하나 쌍극자(dipole)를 갖는 표면 이 극성의 물에 대해 무조건 친수성을 보이는 것은 아 니며, 표면에 흡착되는 물 분자 간의 간격이 특정 거리 (critical length)보다 짧으면 물 분자 간의 척력으로 인 해 소수성이 된다는 계산 결과를 보고한다 ${ }^{33)}$. 불소 원자 의 공유 결합에 의한 그래핀의 탄소 원자 간의 격자 거 리가 수소화 그래핀의 격자 거리보다 짧은 점 ${ }^{34,35)}$, 그 (a) UNSTABLE

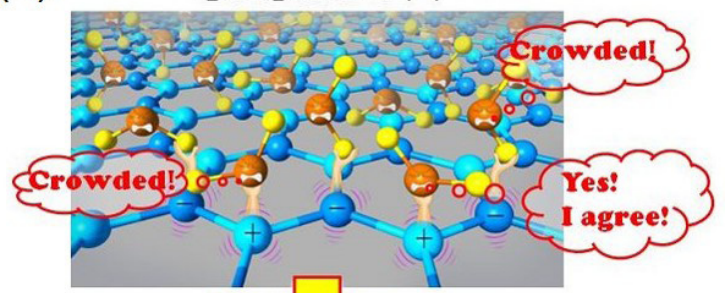

Relaxing

STABLE

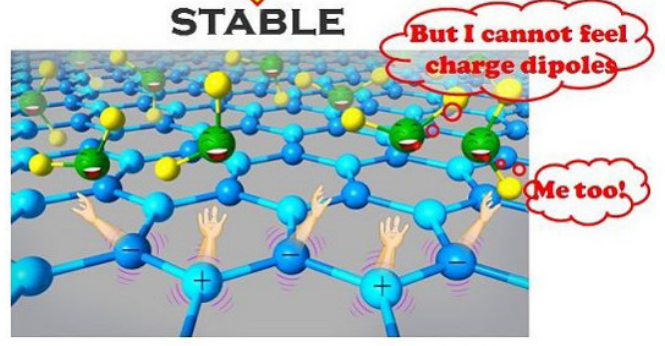

(b)

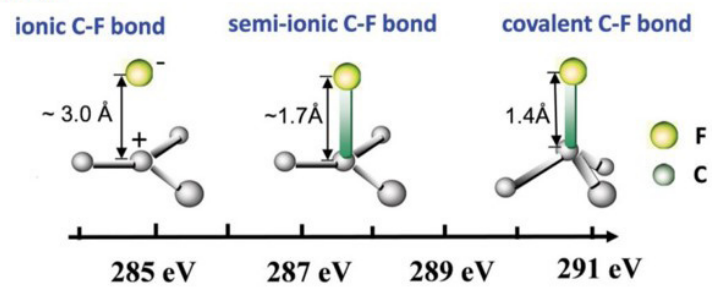

Fig. 11. (a) 표면 전하의 거리에 따른 물 분자의 흡착 안정성을 묘 사하는 모식도. 표면 전하 사이의 거리가 좁으면 물 분자의 흡착이 어려워, 표면이 소수성을 보임. ${ }^{33)}$ (b) C-F 결합의 길이와 XPS로부터 측정되는 $\mathrm{C} 1 \mathrm{~s}$ 스펙트럼 내 C-F 결합의 특성 피크(characteristic peaks) ${ }^{36)}$.

리고 불화 그래핀은 C-F 공유 결합뿐만 아니라 semiionic $\mathrm{C}-\mathrm{F}$ 결합도 표면에 존재하므로(Fig. 11(b) $)^{36)}$ 수 소화 그래핀에 비해 표면 전하의 밀도가 높다는 점으로 인해 critical length보다 짧은 거리에 흡착된 물 분자간 의 척력이 불화 그래핀 표면을 소수성으로 만든다는 것 이 보다 설득력이 있어 보이지만, 명확한 실험적 근거없 이 이를 단정지을 수는 없는 상황이다. 따라서, 이에 대 한 명확한 실험 결과가 곧 보고되길 바라며, 본 논문에 서는 불화 그래핀이 왜 소수성을 나타내는지에 대한 언 급보다는 화학적 기능화를 통한 불화 그래핀의 습윤성 결과에 대한 소개에만 집중하기로 하겠다.

University of Chemistry and Technology Prague 
연구진은 불화 그래핀이 소수성임을 보고하였고, 불소 의 흡착률 증가에 따라 소수성이 강해져 최대 $142.2^{\circ}$ 의 접촉각이 관찰됨을 보였다 ${ }^{37)}$. 또한 경기대학교 연구진 은 $\mathrm{CF}_{4}$ 플라즈마를 이용하여 불화 그래핀의 습윤성을 보고하였는데 ${ }^{38)}$, 약 20 초 동안 처리한 초기 불화 그래핀 은 103 105 가량의 접촉각이 관찰되는 소수성을 보였 으나, 플라즈마 처리 시간이 증가함에 따라 접촉각이 낮 아져 친수성으로 변화되는 현상을 보고하였다. 연구진 은 contact angle이 낮아지는 이유를 플라즈마 처리에 의한 결함 발생이 표면 에너지를 증가시키기 때문이라 고 보고하였고, 이는 불화 그래핀의 친수성이 확인될 경 우 결함 발생으로 인한 가능성을 필히 확인해야 함을 시 사한다.

지금까지 소개한 결과들은 한 종류의 원자를 그래핀 의 표면에 화학적으로 흡착시켜 그 습윤성을 보고한 결 과들이었다. 이와는 다르게, 서로 다른 원자를 동일 한 그래핀 표면에 국부적으로 흡착시켜 각기 다른 화학 적 기능화 표면의 습윤성을 보고한 결과가 University of Illinois Urbana-Champaign 연구진에 의해 보고 되었는데 ${ }^{39)}$, 그래핀, 수소화 그래핀, 불화 그래핀, 그리 고 수소와 불소가 동시에 존재하는 hydrofluorinated graphene의 습윤성을 동시에 비교한 결과이다(Fig 12 (a)와 (b)). 본 연구에서도 불화 그래핀은 소수성의 표 면 특성을 보였고, 수소화 그래핀은 친수성의 표면 특성 을 보였다(Fig 12(c)). 흥미로운 점은 hydrofluorinated graphene의 습윤성인데, 수소와 불소가 혼합된 그래핀 표면은 친수성과 소수성의 중간 상태를 보였고, 이는 이 종 원자들의 혼합을 통해 그래핀의 습윤성을 제어할 수 있음을 시사한다. 또한 본 연구에서 사용한 화학적 기능 화의 패터닝 기법을 이용하면 소수성과 친수성 영역이 혼재된 복합 패터닝이 가능한데, 이렇게 제작한 그래핀 의 표면은 lab-on-chip이나 microfluidic 연구에도 적 용이 가능할 것이다.

\section{4. 맺음말}

지금까지 그래핀의 습윤성 및 제어 기술들에 대해 살 (a)

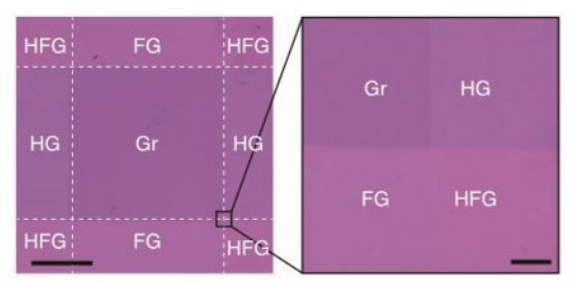

(b)

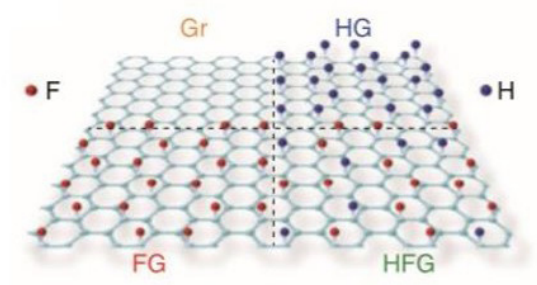

(c)

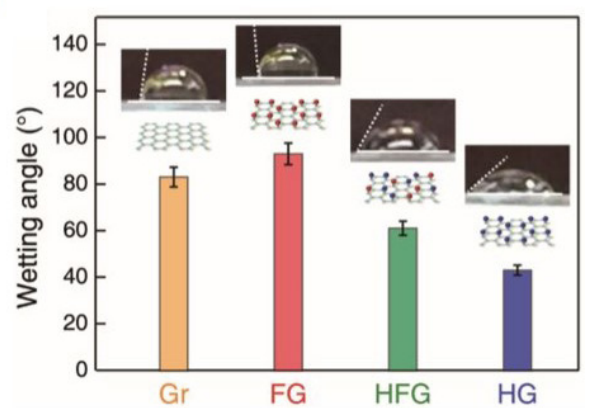

Fig. 12. (a,b) 그래핀(Gr), 수소화 그래핀(HG), 불화 그래핀(FG), hydrofluorinated graphene(HFG)를 동시에 구현한 표면 의 광학 이미지 및 모식도. (c) 그래핀 및 화학적 기능화된 각 표면의 접촉각 3 .

펴보았다. 그래핀은 일반적으로 소수성으로 알려져있으 나, 최근 보고된 여러 연구 결과들에 의하면 아직까지는 그래핀의 습윤성에 대한 결론을 내리기 어려운 실정이 다. 그러나 그래핀의 원래 습윤성에 상관없이 표면 제어 기술을 통하여 원하는 습윤성으로 조절하는 것이 가능 한데, 표면의 구조를 변형시키거나 화학적 상태를 변형 시켜 소수성 및 친수성의 그래핀으로 제어하는 연구 결 과들이 보고되었다. 그리고 이러한 습윤성 제어 기술을 활용하여 탄소 기반의 전자 소자 및 바이오 소자로의 광 범위한 응용이 가능하다. 본 리뷰 논문이 그래핀 및 이 차원 재료의 표면 연구를 하는 연구자들에게 조금이나 마 도움이 되길 바라며, 그래핀의 습윤성에 대한 연구가 더욱 활발히 진행되어 여전히 불명확한 현상들이 훗날 명확히 밝혀지기를 고대한다. 


\section{5. 감사의 글}

본 논문은 KIST 주요사업(2K02420, 2Z06030)의 지원을 받아 수행되었음.

\section{REFERECES}

1. J. Feng and Z. Guo, "Wettability of Graphene: from Influencing Factors and Reversible Conversion to Potential Applications," Nanoscale Horiz., 4 339-64 (2019).

2. L. Zhong, H. Zhu, Y. Wu and Z. Guo, "Understanding How Surface Chemistry and Topography Enhance Fog Harvesting based on the Superwetting Surface with Patterned Hemispherical Bulges," J. Colloid Interface Sci., 525 234-42 (2018).

3. J. Li and Z. Guo, "Spontaneous Directional Transportations of Water Droplets on Surfaces Driven by Gradient Structures," Nanoscale, 10 13814-31 (2018).

4. X. Jing and Z. Guo, "Biomimetic Super Durable and Stable Surfaces with Superhydrophobicity, "J. Mater. Chem. A, 6 16731-68 (2018).

5. C. Huang and Z. Guo, "The Wettability of Gas Bubbles: from Macro Behavior to Nano Structures to Applications," Nanoscale, 10 19659-72 (2018).

6. B. B. Rich and B. Pokroy, "A Study on the Wetting Properties of Broccoli Leaf Surfaces and Their Time Dependent Self-Healing after Mechanical Damage," Soft Matter, 14 7782-92 (2018).

7. S. S. Latthe, P. Sudhagar, A. Devadoss, A. M. Kumar, S. Liu, C. Terashima, K. Nakata and A. Fujishima, "A Mechanically Bendable Superhydrophobic Steel Surface with SelfCleaning and Corrosion-Resistant Properties," J. Mater. Chem. A, 3 14263-71 (2015).

8. T. Niu, J. Zhang and W. Chen, "Surface Engineering of Two-Dimensional Materials," ChemNanoMat, 5 6-23 (2019).

9. A. Boretti, S. Al-Zubaidy, M. Vaclavikova, M. Al-Abri, S. Catelletto and S. Mikhalovsky,
"Outlook for Graphene-Based Desalination Membranes," npj Clean Water, 5 (2018).

10. M. F. El-Kady, Y. Shao and R. B. Kaner, "Graphene for Batteries, Supercapacitors and Beyond," Nat. Rev. Mater., 116033 (2016).

11. R. Raj, S. C. Maroo and E. N. Wang, "Wettability of Graphene," Nano Lett., 13 1509-15 (2013).

12. D. Parobek and H. Liu, "Wettability of Graphene," 2D Mater., 2032001 (2015).

13. L. A. Belyaeva and G. F. Schneider, "Wettability of Graphene," Surf. Sci. Rep., 75 100482 (2020).

14. P. Snapp, J. M. Kim, C. Cho, J. Leem, M. F. Haque and S. W. Nam, "Interaction of 2D Materials with Liquids: Wettability, Electrochemical Properties, Friction, and Emerging Directions," NPG Asia Materials, 12 22 (2020).

15. J. Rafiee, X. Mi, H. Gullapalli, A. V. Thomas, F. Yavari, Y. Shi, P. M. Ajayan and Nikhil Koratkar, "Wetting Transparency of Graphene, "Nat. Mater., 11 217-22 (2012).

16. Z. Li, Y. Wang, A. Kozbial, G. Shenoy, F. Zhou, R. McGinley, P. Ireland, B. Morganstein, A. Kunkel, S. P. Surwade, L. Li and H. Liu, "Effect of Airborne Contaminants on the Wettability of Supported Graphene and Graphite," Nat. Mater., 12 925-31 (2013).

17. F. Taherian, V. Marcon, N. F. A. van der Vegt and F. Leroy, "What Is the Contact Angle of Water on Graphene?," Langmuir, 29 1457-65 (2013).

18. G. Scocchi, D. Sergi, C. D’Angelo and A. Ortona, "Wetting and Contact-Line Effects for Spherical and Cylindrical Droplets on Graphene Layers: A Comparative MolecularDynamics Investigation," Phys. Rev. E, 84 061602 (2011).

19. J. E. Andrew, S. Sinha, P. W. Chung and S. Das, "Wetting Dynamics of a Water Nanodrop on Graphene," Phys. Chem. Chem. Phys., 18 23482-93 (2016)

20. G. Yiapanis, A. J. Makarucha, J. S. Baldauf and M. T. Downton, "Simulations of Graphitic 
Nanoparticles at Air - Water Interfaces," Nanoscale, 8 19620-28 (2016).

21. D. G. Papageorgious, I. A. Kinloch and R. J. Young, "Mechanical Properties of Graphene and Graphene-Based Nanocomposites," Prog. Mater. Sci., 90 75-127 (2017).

22. W. Xiong, J. Z. Liu, Z.-L. Zhang and Q. - S. Zheng, "Control of Surface Wettability via Strain Engineering," Acta Mechanica Sinica, 29 543-49 (2013).

23. S. Zhang, J. Huang, Z. Chen and Y. Lai, "Bioinspired Special Wettability Surfaces: From Fundamental Research to Water Harvesting Applications," Small, 131602992 (2017).

24. L. Makkonen, "Young's equation revisited," J. Phys.: Condens, Matter, 28135001 (2016).

25. R. N. Wenzel, "Resistance of Solid Surfaces to Wetting by Water," Ind. Eng. Chem., 28 98894 (1936).

26. A. B. D. Cassie and S. Baxter, "Wettability of Porous Surfaces," Trans. Faraday Soc., 40 546-51 (1944).

27. J. Dong, Z. Yoo, T. Yang, L. Jiang and C. Shen, "Control of Superhydrophilic and Superhydrophobic Graphene Interface," Sci. Rep., 31733 (2013).

28. E. Singh, Z. Chen, F. Houshmand, W. Ren, Y. Peles, H.-M. Cheng and N. Koratkar, "Superhydrophobic Graphene Foams," Small, 9 75-80 (2013).

29. J. Zang, S. Ryu, N. Pugno, Q. Wang, Q. Tu, M. J. Buehler and X. Zhao, "Multifunctionality and Control of the Crumpling and Unfolding of Large-Area Graphene," Nat. Mater., 12 321-25 (2013).

30. Y. J. Shin, Y. Wang, H. Huang, G. Kalon, A. T. S. Wee, Z. Shen, C. S. Bhatia and H. Yang, "Surface-Energy Engineering of Graphene," Langmuir, 26 3798-802 (2010).

31. C. J. Russo and L. A. Passmore, "Controlling Protein Adsorption on Graphene for Cryo-EM using Low-Energy Hydrogen Plasmas," Nat. Methods, 11 649-652 (2014).

32. J. Son, J.-Y Lee, N. Han, J. Cha, J. Choi, J.
Kwon, S. W. Nam, K. -H. Yoo, G. -H. Lee and J. Hong, "Tunable Wettability of Graphene through Nondestructive Hydrogenation and Wettability-Based Patterning for Bioapplications," Nano Lett., (2020).

33. C. Wang, B. Zhou, Y. Tu, M. Duan, P. Xiu, J. Li and H. Fang, "Critical Dipole Length for the Wetting Transition Due to Collective Waterdipoles Interactions," Sci. Rep., 2358 (2012).

34. Y. Li and Z. Chen, "Patterned Partially Hydrogenated Graphene $\left(\mathrm{C}_{4} \mathrm{H}\right)$ and Its OneDimensional Analogues: A Computational Study," J. Phys. Chem. C, 116 4526-4534 (2012).

35. H. Sahin, M. Topsakal and S. Ciraci, "Structures of Fluorinated Graphene and Their Signatures," Phys, Rev. B, 83115432 (2011).

36. W. Feng, P. Long, Y. Feng and Y. Li, "TwoDimensional Fluorinated Graphene: Synthesis, Structures, Properties and Applications," Adv. Sci., 31500413 (2016).

37. V. Mazánek, O. Jankovský, J. Luxa, D. Sedmidubský, Z. Janoušek, F. Šembera, M. Mikulics and Z. Sofer, "Tuning of Fuorine Content in Graphene: Towards Large-Scale Production of Stoichiometric Fuorographene," Nanoscale, 713646 (2015).

38. T. Lim and S. Ju, "Control of Graphene Surface Wettability by Using $\mathrm{CF}_{4}$ Plasma," Surf. Coat. Tech., 328 89-93 (2017).

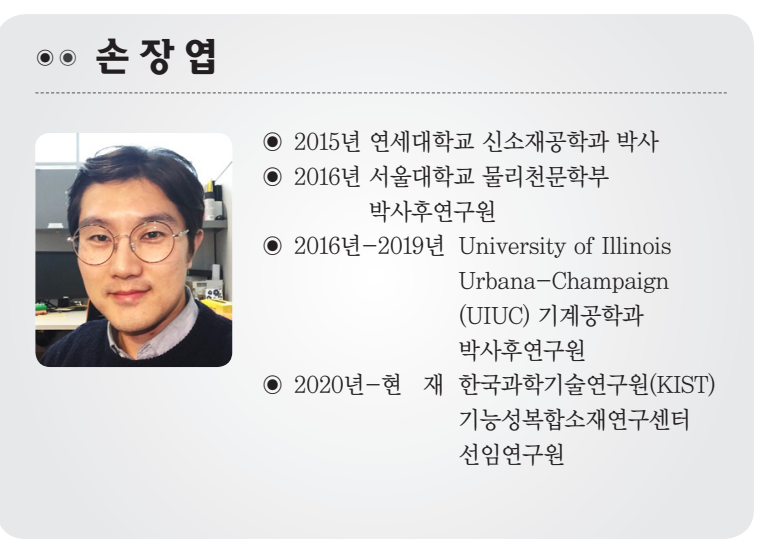

